\title{
Safer Care - \\ Measuring to Manage and Improve
}

$\overline{\text { Kira Leeb, Jennifer Zelmer, Greg Webster and Indra Pulcins }}$

\section{As}

early as the 17 th century BC, Hammurabi's Code acknowledged that harm might result from medical care. Interest in measuring patient safety to support quality improvement emerged more recently, but is by no means new. Around 1910, for example, Ernest Codman advocated a focus on "end results," taking comprehensive measurements during and following care in order to help prevent undesirable outcomes. Similarly, Florence Nightingale documented survival rates for surgical patients during the Crimean War.

Fast-forward to today and patient safety is on the agenda worldwide. In Canada the first nationwide study of adverse events in hospitals was published in 2004 (Baker et al. 2004). Healthcare providers, the new Canadian Patient Safety Institute, provincial institutes and task forces, and many others are working to respond to the results of the study.

While medical practice has changed since the days of Ernest Codman, what has not changed is the focus on having good information to guide quality improvement efforts. Measures are required at a variety of levels (see Figure 1). For instance, broad-based global metrics provide information about the prevalence of adverse events and their impact on patients. Healthcare organizations often seek to track patient safety outcomes for their patients, as well as related processes of care. Individual quality improvement teams also require detailed information to monitor their progress in specific areas. This information may be collected as part of rapid cycle improvement or other change processes and will evolve over time depending on the focus of quality improvement efforts.

Figure 1: Measuring for Safety

Understanding the state of patient safety is an important step towards achieving safer care. A century ago, this information was rarely available, with scattered tracking primarily by individual care providers interested in safer care. Today, information is available from a broader range of standard and special purpose sources. Information collected from an organizational perspective (e.g., at the level of a hospital) helps to identify where problems may exist and tracks improvements in care. Information from the global perspective provides a populationbased measure of patient safety, a first step in enabling jurisdictions to compare their results over time and with others.

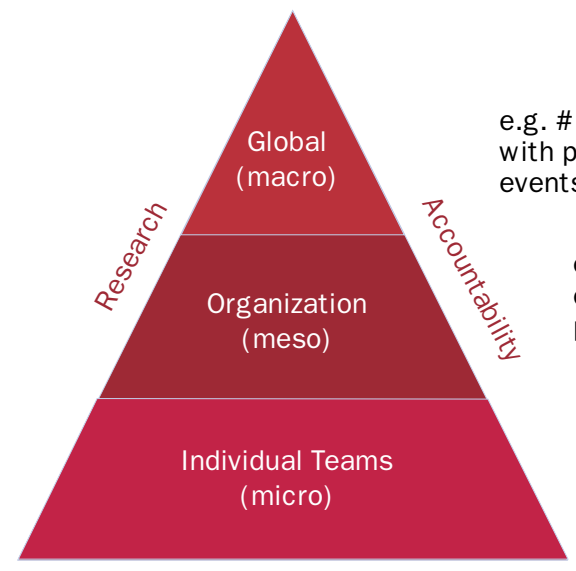

Quality Improvement e.g. \# deaths associated with preventable adverse

e.g. trends in safety outcomes or care processes

e.g. tracking a team's care processes 


\section{From the Global Perspective}

In 2004 approximately one in four (23\%) Canadian adults 15 years and older said that they or a member of their family had experienced an adverse event related to their medical care (Canadian Institute for Health Information 2004). That translates to about 5.2 million people across the country. Almost a third (30\%) said that the most recent event happened within the last year.

In hospitals, the largest study in Canada of adverse events found that between 9,250 and 23,750 medical and surgical adult patients with overnight hospital stays in 2000-2001 experienced a preventable adverse event and later died (Baker et al. 2004). Interestingly, the public tends to estimate much lower numbers of deaths. In 2003-2004 the Canadian Institute for Health Information (CIHI) commissioned a telephone survey of just over 4,200 adults across the country. Only $7 \%$ of respondents thought that 10,000 or more Canadians die in hospital each year from preventable adverse events (Canadian Institute for Health Information 2005a). Another $21 \%$ said that they did not know how many people died annually. Similarly, most respondents to a 2000 survey in the U.S. believed that fewer in-hospital deaths due to preventable errors occurred than estimated by authors of a landmark study by the Institute of Medicine (Blendon et al. 2002).

While many studies provide overall estimates of adverse event rates, more detailed research demonstrates that the frequency of specific types of adverse events varies widely. For example, adverse events related to medications are much more common than those related to infected blood transfusions (see Table 1). Emerging data also suggest that rates may vary significantly from one part of the country to another. Regional in-hospital hip fracture rates, for instance, ranged from 0.5 to 3.4 per 1,000 seniors admitted to Canadian acute care hospitals in 2001-2002 to 2003-2004 (excludes Quebec and Manitoba) (Canadian Institute for Health Information 2005b).
Table 1: How Often Various Types of Adverse Events Occur

\begin{tabular}{|c|c|}
\hline Event Type & Rate \\
\hline $\begin{array}{l}\text { Reporting having been given the wrong medica- } \\
\text { tion or the wrong dose by a doctor, hospital or } \\
\text { pharmacist in the past } 2 \text { years** }\end{array}$ & $\begin{array}{l}1 \text { in } 9 \text { adults with health } \\
\text { problems }\end{array}$ \\
\hline $\begin{array}{l}\text { Contracting a healthcare-related infection while } \\
\text { in an acute care hospital } * * * *\end{array}$ & $\begin{array}{l}1 \text { in } 9 \text { adults } \\
1 \text { in } 11 \text { children }\end{array}$ \\
\hline $\begin{array}{l}\text { Experiencing an adverse event in an acute care } \\
\text { hospital* }\end{array}$ & $\begin{array}{l}1 \text { in } 13 \text { adult medical/ } \\
\text { surgical patients }\end{array}$ \\
\hline $\begin{array}{l}\text { Reporting an adverse event in the past year for } \\
\text { oneself or a family member*** }\end{array}$ & 1 in 16 adults \\
\hline Third/fourth-degree tears during childbirth & $\begin{array}{l}1 \text { in } 20 \text { mothers who deliver } \\
\text { vaginally in hospital }\end{array}$ \\
\hline $\begin{array}{l}\text { Birth trauma (e.g. bone, scalp or spinal cord } \\
\text { injury at birth)§ }\end{array}$ & 1 in 81 newborns \\
\hline $\begin{array}{l}\text { Death associated with a "preventable" adverse } \\
\text { event in an acute care hospital* }\end{array}$ & $\begin{array}{l}1 \text { in } 152 \text { adult medical/ } \\
\text { surgical patients }\end{array}$ \\
\hline Adverse transfusion reactions§ & $\begin{array}{l}1 \text { in } 299 \text { patients who } \\
\text { receive a transfusion in } \\
\text { hospital }\end{array}$ \\
\hline In-hospital hip fractures§ & $\begin{array}{l}1 \text { in } 1,250 \text { hospitalized } \\
\text { seniors }\end{array}$ \\
\hline Foreign object left in after procedure§ & $\begin{array}{l}1 \text { in } 6,667 \text { medical/ surgical } \\
\text { patients }\end{array}$ \\
\hline Hepatitis B infected blood ${ }^{a}$ & $\begin{array}{l}1 \text { in } 72,046 \text { units of trans- } \\
\text { fused blood }\end{array}$ \\
\hline Hepatitis C infected blood ${ }^{a}$ & $\begin{array}{l}1 \text { in } 2,857,143 \text { units of trans- } \\
\text { fused blood }\end{array}$ \\
\hline HIV-infected blood ${ }^{a}$ & $\begin{array}{l}1 \text { in } 10,000,000 \text { units of } \\
\text { transfused blood }\end{array}$ \\
\hline
\end{tabular}

Sources:

* G. R. Baker et al., "The Incidence of Adverse Events in Canadian Hospitals," Canadian Medical Association Journal, 170,11 (2004):1678-1686.

** From: R. J. Blendon, C. Schoen, C. DesRoches, R. Osborn, K. Zapert, "Common Concerns Amid Diverse Systems: Health Care Experiences in Five Countries," Health Affairs 22, 3 (2003):106-121.

*** Canadian Institute for Health Information (survey conducted by The Berger Population Health Monitor) (Toronto: CIHI, 2004); includes adults 15 years of age and older.

$* * * *$ From Canadian Nosocomial Infection Surveillance Program and the Canadian Hospital Epidemiology Committee of Health Canada. § Discharge Abstract Database for 2001-2002 to 2003-2004, CIHI a From: J. A. Chiavetta, M. Escobar, A. Newman, Y. He, P. Driezen, S. Deeks, D. Hone, S. O'Brien, G. Sher, “Incidence and Estimated Rates of Residual Risk for HIV, Hepatitis C, Hepatitis B and Human T-cell Lymphotropic Viruses in Blood Donors in Canada, 1990-2000," Canadian Medical Association Journal 169, 8 (2003): pp. 767-773. Estimates based on units of donated blood. Excludes Quebec.

Note: The figures above are based on point estimates of adverse event rates. See the original references for more information on confidence intervals around these estimates. 


\section{A View from the Organizational Perspective}

Knowing the extent to which adverse events occur within a population provides a baseline from which to start to measure change. However, individual health care organizations may also use more detailed qualitative and quantitative measures to track their progress towards safer care and to identify opportunities for quality improvement.

One option is to compare outcomes with other similar healthcare providers. The majority of hospital executives in all five countries surveyed by the Commonwealth Fund in 2003 felt that this approach would be somewhat or very effective in improving quality of care (see Figure 2) (Blendon et al. 2004). Compared with other countries, Canadian hospital executives were among the most supportive of disclosing quality information, such as the rates of nosocomial infections and medical errors, to the public.

Already, a number of initiatives are underway that build on these premises. For example, a number of health regions and hospitals across the country participate in the CIHI/Hay Group Benchmarking Comparison of Canadian Hospitals. In recent years, this project has included a range of patient safety indicators. At a regional level, comparable data on selected outcomes of care (e.g., 30-day in-hospital acute myocardial infarction mortality) and patient safety (e.g., in-hospital hip fracture rates) are produced through the CIHI/Statistics Canada Health Indicators Project. There are also several provincial initiatives and efforts to provide comparable information for different specialty areas.

Additional initiatives are also emerging. For example "Safer Healthcare Now!", a grassroots patient safety campaign aimed at reducing preventable complications and deaths, is testing the use of intervention-specific process and outcome measures, as well as broad-based safety indicators. Originally developed in the United Kingdom, Hospital Standardized Mortality Ratios (HSMRs) compare observed versus expected deaths on a hospital-specific basis, adjusted for the age, sex, diagnoses, and admission status of its patients (Jarman et al. 2005). The Institute for Healthcare Improvement in the United States is now using this measure to track the success of its 100,000 Lives patient safety campaign, and it will be a core measure for the Canadian Safer Healthcare Now! campaign.

HSMRs provide a baseline from which hospitals can track and compare their results over time. In 2000, for example, the Walsall Hospitals NHS Trust in England had 1,080 deaths compared with the 830 that would be expected based on the
Figure 2: Outcome Comparisons and Improving the Quality of Care

In 2003 hospital executives from five countries were asked how effective they thought having outcome comparisons with other hospitals would be in improving quality of care. Over $80 \%$ in each country, including Canada, felt they would be either a somewhat or very effective means mechanism for quality improvement.

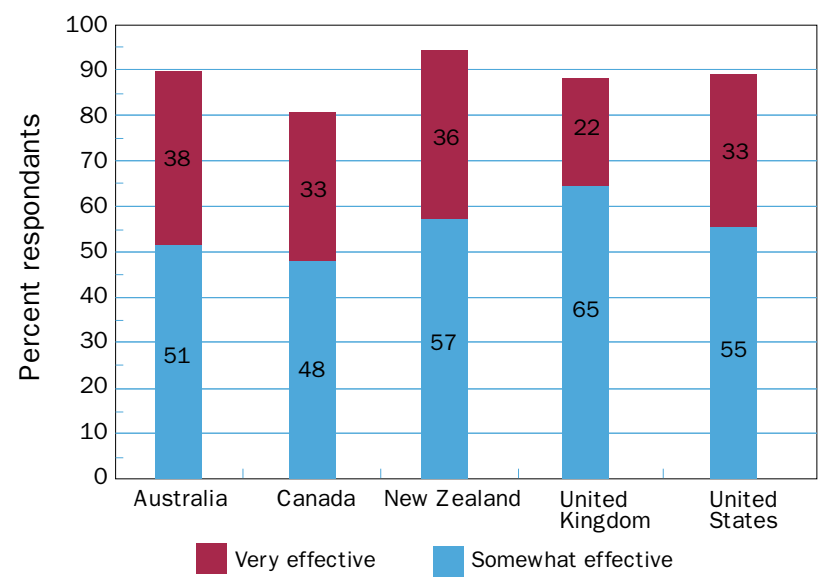

Source: Blendon R.J., C. Schoen, C. M. DesRoches, R. Osborn, K. Zapert, and E. Raleigh. 2004. "Confronting Competing Demands To Improve Quality: A Five-Country Hospital Survey." Health Affairs, 23(3):119-35.

patient mix that they cared for (Jarman et al. 2005). This translates into an HSMR or 130, the highest level of any hospital in the country at the time. Through a series of concerted improvements, over a four-year period they reduced their HSMR to 93. That represents a reduction of 295 observed compared with expected deaths per year.

\section{From the Team Perspective}

Measurement is at the heart of many quality improvement efforts. For example, Plan, Do, Study, Act (PDSA) cycles are being used by healthcare teams across Canada and around the world. This approach uses pragmatic data collection and measurement activities to inform and support incremental changes in the process of care. For the local teams leading these initiatives, measurement is not the goal; rather it is a tool that facilitates progress towards the goal. Unlike measurement for research, data used by quality improvement teams often involves smaller samples and less complex collection methods (Institute for Healthcare Improvement 2005).

In some cases, teams may be able to build on shared approaches to data collection and analysis. For example, The 
Guidelines Applied in Practice (GAP), endorsed by the American Heart Association and widely accepted internationally, outlines five specific practices at time of discharge that have been shown to reduce mortality in patients with heart disease (Parsons et al. 2002). Application of GAP-related improvements is one of six strategies in Safer Healthcare Now! The campaign intends to provide tools that can be used by individual teams to track their progress over time.

\section{CONCLUSIONS}

According to the World Health Organization (WHO), adverse events represent "a challenge to quality of care, a significant avoidable cause of human suffering, and a high toll in financial loss and opportunity cost to health services" (WHO 2002). To address this challenge, $\mathrm{WHO}$, in conjunction with its partners, launched the World Alliance for Patient Safety in October 2004 to reduce the number of preventable illnesses, injuries, and deaths patients experience during their care.

In Canada and elsewhere, in order to know whether progress is being made and where further opportunities for improvement might exist, high-quality information is required at multiple levels. At a macro level, we need to know how many Canadians experience preventable adverse events, as well as how the situation is changing over time. As Ernst Codman pointed out almost a century ago, health regions and healthcare providers also need more detailed information to understand the progress of their quality improvement initiatives and patient outcomes following care. And finally, healthcare teams can test rapid improvement strategies by collecting and rapidly responding to data that tracks the results of their efforts.

\section{References}

Baker G. R., P. G. Norton, V. Flintoft, R. Blais, A. Brown, J. Cox, E. Etchells, W. A. Ghali, P. Hébert, S. R. Majumdar, M. O’Beirne, L. Palacios-Derflingher, R. J. Reid, S. Sheps and R. Tamblyn. 2004. "The Canadian Adverse Events Study: the incidence of adverse events among hospital patients in Canada." Canadian Medical Association Journal 170(11): 1678-86.

Blendon, R. J., C. M. DesRoches, M. Brodie, J. M. Benson, A. B. Rosen, E. Schneider, D. E. Altman, K. Zapert, M. J. Herrmann, and A. E. Steffenson. 2002. "Views of Practicing Physicians and the Public on Medical Errors." New England Journal of Medicine 347(24): 1933-40.

Blendon R.J., C. Schoen, C. M. DesRoches, R. Osborn, K. Zapert, and E. Raleigh. 2004. "Confronting Competing Demands To Improve Quality: A Five-Country Hospital Survey." Health Affairs 23(3): 119-35.
Canadian Institute for Health Information (CIHI). 2004. Health Care in Canada, 2004. Ottawa.

Canadian Institute for Health Information (CIHI). 2005a. "The Berger Population Health Monitor." Ottawa. (Unpublished, 2004.)

Canadian Institute for Health Information (CIHI). 2005b. Health Indicators, 2005. Ottawa.

Institute for Healthcare Improvement. 2005. Measures. http://www. ihi.org/IHI/Topics/Improvement/ImprovementMethods/Measures/.

Jarman B., A. Bottle, P. Aylin, and M. Browne. 2005. "Monitoring changes in hospital standardized mortality rations." British Medical Journal 330: 329.

Parsons L.S., C.V. Pollack, K. Newby, and K.A. Littrell. 2002. "Death rates lower in hospitals that follow heart attack guidelines." American Heart Association's Scientific Sessions 2002: Abstract 3557.

World Health Organization. 2002. "Quality of Care: Patient Safety." Report by the Secretariat to the Fifty-Fifth World Health Assembly. Geneva.

\section{About the Authors}

Kira Leeb, MA, Manager, Health Services Research, has managed the production of ClHI's annual report on the health of Canada's healthcare system and has led the production of more focused reports or research on Canada's healthcare system.

Jennifer Zelmer, PhD, is Vice-President, Research and Analysis. In this role, Dr. Zelmer leads an integrated program of health services and population health-related analytical and research initiatives.

Greg Webster, MSc, Director, Research and Indicator Development. In this role, Mr. Webster is responsible for providing vision, leadership and direction in fostering $\mathrm{ClHI}$ 's relationships with the health services research community, in developing comparative health indicators and in enhancing $\mathrm{ClHI}$ 's analytical capacity.

Indra Pulcins, PhD, Manager, Health Indicators. Dr. Pulcins conducts health services research and is responsible for the development of health indicators at $\mathrm{ClHI}$, with a particular focus on outcomes and patient safety.

Corresponding Author: Greg Webster, Director, Research and Indicator Development, Canadian Institute for Health Information (CIHI), 90 Eglinton Avenue East, Suite 300, Toronto, Ontario M4P 2Y3, Phone: (416) 481-1616 Ext. 3508, Fax: (416) 481-2950, email: gwebster@cihi.ca,web-site: www.cihi.ca 